\title{
SOME ASPECTS OF REGULATORY OPTIMIZATIONS IN THE FINANCIAL SECTOR
}

\author{
Stefan Vachkov ${ }^{1}$, Nedyalko Valkanov ${ }^{2}$
}

Received: 7.12.2020, Accepted: 22.12.2020

\begin{abstract}
Rapid development of the high technologies sector undoubtedly reflects the present-day financial regulation. Innovations like blockchain, cloud computing and artificial intelligence underlie the foundations of newly appeared RegTech firms and SupTech initiatives and quickly appear in the toolbox of contemporary financial supervision. The article examines some key trends related to their involvement and implementation by financial institutions and supervisors. Several arguments supporting the thesis for gradual transition to a more integrated and interactive model of financial regulation, characterized by a change from institutional to platform financial regulatory infrastructure, are presented.
\end{abstract}

Keywords: financial regulations; blockchain; artificial intelligence; big data; FinTech; RegTech; SupTech

JEL Codes: G18, G28, O30

\section{Introduction}

In the era of large-scale digital transformations, the financial sector needs a skillful management of the regulatory "climate". Innovations like Open Banking, Cloud Computing, Blockchain, Artificial Intelligence (AI) and Machine Learning (ML) possess a large creative potential for: increase in the digital data volumes; "enrichment" of the value offer; imposition of a unified approach to the risk management; evolution in customer experiences; emergence of new market players with advanced business models, and etc. Their contribution to the increasingly tangible change in traditional channels for providing financial products and services is also indisputable. Neobanks, money transfer blockchainbased platforms, crowdfunding and P2P networks, the transformation of some global

\footnotetext{
${ }^{1}$ Prof., Ph. D., University of Economics - Varna, Department of Finance, e-mail: vachkov@uevarna.bg, ORCID ID: https://orcid.org/0000-0002-6716-3301

2 Assoc. Prof., Ph. D., University of Economics - Varna, Department of Finance, e-mail: n.valkanov@ue-varna.bg, ORCID ID: https://orcid.org/0000-0003-2394-7785
} 
technology companies (BigTechs) into providers of financial services are only some illustrations for the substantial change in financial landscape. The logical consequence from that change is the transformation in the field of financial regulation. From a normative point of view, the "modernization" of the regulatory framework is more than visible through the introduction of new and renewal of existing regulations. For example, PSD2 practically institutionalizes the revolution in the field of transfer operations, giving a green light for the development of "open banking". However, the regulatory burden emerges as a key challenge for financial institutions ${ }^{1}$.

The article outlines several high-tech trends from recent years, that change the vision of financial regulation and assist to mitigate the excessive regulatory load financial institutions are forced to bear. Marked high-tech innovations are considered as basis for reformatting the overall supervisory framework in direction of creating an integral and interactive environment for financial regulatory activities. Considering these circumstances below are presented arguments in support of the thesis for a gradual transition to a more integrated and interactive model of financial regulation, characterized by a change from institutional to platform-based financial regulatory infrastructure. As a conclusion are outlined several possible scenarios for future development in short-term and long-term period.

\section{High-tech and financial regulation - an inevitable cooperation}

The period following the global financial crisis of 2007-2008 is characterized by significant regulatory change, introduction of new and renewal of a remarkable number of existing regulations. Their implementation into the practice of financial institutions becomes a top priority, and the assumption of inefficiency often means imposition of significant sanctions for noncompliance. There is no doubt about the hardship that regulatory compliance units are facing with ${ }^{2}$. Implementing and ensuring compliance with regulations like EMIR (2013), CSMAD and MAR (2014), AMLD 4 (2015), Solvency II (2016), SFTR (2016), CSDR (2017), AMLD 5 (2018), GDPR (2018), IFRS 9 (2018), MiFID 2 (2018), PSD 2 (2018) cost the financial sector tens of billions of dollars. Moreover, increases in the order of hundreds of percent could be found when comparing the levels of compliance costs for 2017 with those for 2008! For example, during the mentioned period current compliance costs of operating in EU investment banks increased 46 times, while their one-time investment costs increased by $620 \%$. In 2008 , the average current compliance costs of other banking institutions amount to $€ 5$ million, while in 2017 their volume already reaches $€ 43$ million. For their part, in 2008 the average compliance 
costs of European asset management funds totaled $€ 1.6$ million which volume rises to $€$ 32 million in 2017 (European Commission, 2019, p. 9).

Very indicative in this respect is the finding that only in banking a regulatory change happens every 12 minutes (Skinner, 2017). Against this background, the involvement of RegTech companies in the regulatory infrastructure is proving to be a lifeline for traditional financial institutions ${ }^{3}$.

Appearance of RegTech firms could be associated with the FinTech sector, but unlike it, their focus is not purely financial and extends to other areas ${ }^{4}$. Also, while the rise of FinTech companies has been fueled by many emerging startups in direct competition with traditional financial institutions, the entry of RegTech firms appears to be a response to the institutional demand for a top-down regulatory expertise - a direct result of rising regulatory compliance costs (Barberis et al., 2019, p. vi).

A research of Deloitte (2016) identifies following four key characteristics of RegTech: 1) agility for de-coupling and organization of large data sets through "Extract, Transfer, Load (ETL) technologies; 2) speed in configuring, generating and processing information for regulatory reporting; 3 ) integration in term of getting solutions and running in short timeframes, and 4) smart analytical tools allowing manipulation and of large data sets (Deloitte, 2016, p. 5).

Despite the huge number and variety of different RegTech areas, following profiles of their product range could be systematized:

- basic compliance decisions, related to instruments for covering basic regulatory and supervisory requirements;

- products for monitoring of operations - monitoring and analysis of interrelations in wire transfers, card operations, securities transactions, used primarily, but not limited to, the anti-money laundering and anti-terrorist financing activities;

- customer identification and verification (including digital identity) management modules, which application appears to be critical after introduction of the PSD 2 regulation and the entry of open banking and non-banks;

- modules for risk management in a broad range of financial areas ${ }^{5}$;

- automated regulatory disclosure and reporting tools, generating various reports and periodically required supervisory inquiries;

- modules for automated monitoring of regulatory changes and advising on their implementation ${ }^{6}$.

The great competitive advantage of the RegTech sector lies in its uniqueness and expertise in information and data management. The tendency to turn into data each activity (the so-called process of datafication) applies in full force to the modern financial 
infrastructure. The huge data sets generated within the daily activities of financial intermediaries require adequate technological support for their processing and analysis not only by the institutions creating them, but also by regulators and other counterparties. In addition, the gradual movement towards decentralized platform models inevitably brings out the necessity to implement the most innovative and modern methods for "smart" data processing, such as: mechanisms for extracting knowledge from data; analysis by analogy; rule-based expert systems; detection of anomalies in databases; machine learning, tools for converting voice and text to computer code, processing information in the cloud, and etc.

The trend towards all over regulation determines the need for a completely new reporting architecture, which to be able to generate information from dozens, and in some cases from hundreds, different information arrays - customer files, analytical reports, registers of transactions, log files with transactions information, payment instruments, archived databases and much more. Meanwhile, traditional information and accounting core systems used by financial intermediaries are not always able to provide all that variety of demanded information. In this respect RegTech firms find themselves in the situation of the necessary external provider of regulatory expertise, facilitating the achievement of regulatory compliance with the increasingly complex external environment.

All this represents a huge opportunity for the RegTech sector to benefit from traditional financial institutions, and especially from banks that are increasingly looking for relief and efficiency in meeting regulatory requirements. Hence, until 2022 processes automation and application of AI - an integral part of the RegTech arsenal, only in customer identification (KYC) area is expected to reduce the time for performance of relevant activities by $90 \%$, generating savings of 5.4 million hours per year (Juniper Research, 2017). A confirmation of these forecasts is the data from 2018 for which year some analyzers report a 2.5 times increase compared to the previous year and almost fivefold increase in investment in the sector over a five-year period. The largest growth for the period 2014-2018 is created by investments for meeting the new regulatory requirements in the field of KYC $(+34.5 \%)$, anti-money laundering (+ 28\%), GDPR $(+13.1 \%)$, MiFID II $(+6.4 \%)$, Basel III $(+2 \%)$, PSD $2(+2 \%)$, and etc. (FinTech Global, 2019).

Therefore, in order to adapt more quickly to present-day realities, financial institutions should not only to adopt new technologies for facilitating their compliance issues with regulatory requirements, but also to integrate them as a key element of their digital transformation agenda. Thereby to banks, asset managers and insurers are being recommended four "correct" options for application of RegTech opportunities: 1) a precise assessment of the needs of the organization; 2) strong understanding of possible solution 
options; 3) acceleration of the efforts for remediation, and 4) creating the proper design of the RegTech solutions and the most suitable operation model it will be engaged with (Pollari et al., 2019).

Examples for RegTech products in this regard are the software platforms for simplification and acceleration of the identification processes and these for transmission of low quality data; the solutions for compliance with different marketing requirements and for creation of dynamic platforms with personalized offers; solutions for compliance with risk management requirements and regulations relying on unique combinations between consulting and regulatory information and technologies. For example, application of AIbased algorithms ensuring end-to-end transparency is considered by some authors (Dzhaparov, 2020) as bringing incomparable benefits in bank risk management and providing possibilities for processing large data arrays by retrieving useful information from vast sets of unstructured data (Dzhaparov, 2020, p. 48).

The benefits from such platforms could be summarized in following three directions (BCBS, 2017, p. 23-24): 1) stimulating the emergence of new processes, distribution channels, products or new business organizations that help banks to comply with regulatory requirements and manage risk more effectively, including through outsourcing or outsourcing processes; 2) implementation of the digital transformation of the control and support functions in banks (risk, compliance, legal, finance, IT); 3) expanding the range of regulatory reporting requirements, financial crime, operational risk (including cybersecurity and fraud detection), consumer and data protection. ${ }^{7}$

Despite the uncertainty surrounding the coronavirus pandemic, RegTech will increasingly support financial institutions to comply with enhanced regulatory requirements. According to a study by Juniper Research, global investments in the sector will increase from approximately $\$ 18$ billion in 2018 to about $\$ 115.9$ billion by 2023 . The largest share of them belongs to North America ( $\$ 41.8$ billion), followed by Western Europe ( $\$ 37.4$ billion) and the rest of the world $-\$ 36.8$ billion. As a result of this increase, in just three years, $40 \%$ of global compliance costs would be "outsourced" to the RegTech sector (Payments NEXT, 2020).

It is logical to expect that regulators will show a growing interest in supervisory technologies and the need for their prudent management. Moreover, they will strive to "remain educated and think proactively about what's new in the market - for example, cryptocurrency. Almost every global regulator - from the UK's FCA to Australia's ASIC - has highlighted technology and RegTech as a priority for the year to come. (...) We've already seen messages from the FCA, FINRA \& the SEC in the US, and ASIC in Australia that RegTech is no longer just a nice-to-have, but something that regulators are expecting 
to be a must-have. Firms need to be looking to stay ahead of the curve and avoid falling behind - both in terms of their peers and regulatory expectation" (Kumar, 2020).

At the same time the European Central Bank places the use of regulatory technologies as a key point that should be taken into account in EU banking regulation. (European Central Bank, 2020, pp. 11-12). In particular, according to the ECB, following widely used by banks digital innovations should be of supervisory interest: 1) the increased use of cloud services, provoking a concentration of several providers of such services (large technology companies); 2) the use of artificial intelligence (AI) in a number of activities (like credit assessment and robot advice); 3) transition to open banking; 4) gaining popularity of the distributed ledger technology (DLT), especially in certain areas like trade financing; 5) compliance with regulatory requirements through the application of RegTech $^{8}$. Similar findings could be found in researches on this issue by various governmental and regulatory agencies ${ }^{9}$.

\section{The high-tech regulators}

The trends towards total digitalization and technologicalization of the financial infrastructure do not pass the activities of regulatory and supervisory institutions.

Taken the lessons from their failure during the global financial crisis of 2007-2008, regulators are aware of the inevitability of their own commitment to the high-tech sphere. This commitment lays the foundations for another new player in the regulatory infrastructure, derived from the unbundling the field of Supervisory Technologies (SupTech) into a separate segment incorporating development and application of different high-tech solutions for the needs of financial regulation and supervision. If for traditional regulatory approaches the "outsourcing" of supervisory activities to external "subcontractors" is unknown and impossible for implementation, thanks to the technological development and the successful positioning of the RegTech sector as a reliable provider of regulatory expertise, nowadays supervisory agencies "open" themselves for such cooperation with the tech sector demonstrating a conceptually new model for interactive communication and cooperation with regulated entities. Such statement is supported by different national and supranational supervisory institutions, according to which the activities in the field of financial regulation are evolving in the direction of more pronounced commitment to the RegTech sector, but also in the direction of strengthening their own high-techn research and development (R\&D) activities ${ }^{10}$.

As an illustration could be highlighted various high-tech regulatory initiatives. Such examples are: 
- The DLT-based decentralized portal for exchange of regulatory information for publicly traded companies in the EU (Financial Transparency Gateway, EFTG), connecting the market infrastructures of individual EU member states which was developed under the auspices of the European Commission.

- The projects undertaken by the monetary authorities of Singapore and Hong Kong, and the Central Bank of Canada, connected with the establishment of blockchain-based infrastructure for exchange of financial information.

- The International Association for Trusted Blockchain Applications (INATBA), established in 2018 under the auspices of the European Commission.

The International Monetary Fund, the European Central Bank, the US Federal Reserve, the financial regulators of Great Britain and Germany, as well as the Swedish Central Bank also carry out their own innovative projects in the field of financial regulation ${ }^{11}$.

In addition, the construction of Regulatory Sandboxes, representing a controlled environment for testing various high-tech solutions, is increasingly common in the practice of financial regulators ${ }^{12}$.

Taking the form of peculiar "incubators" for testing individual supervisory innovations, they facilitate the formation a two-way cooperation between regulators, financial institutions and individual RegTech firms. Here could be mentioned platforms like Corda, Ethereum and HyperLedger Fabric, offering open source basic infrastructure and which could be considered as a kernel for building shared environments with regulators and other government institutions.

According to Deloitte research, similar to the technology of internet browsers, the adoption of unified management standards such as ISO, IEEE and ITU could be seen as a potential to reconfigure the traditional financial infrastructure in terms of servicing various financial activities - account and cash management, lending, risk management, shared financing, securities trading and settlement, cross-border payment processing, trade finance, including better management of trade services by improving the value chain (Deloitte, 2020).

Prioritization of the SupTech initiatives by financial regulators is supported also in the recommendations set out in the Final report of the Expert Group on Regulatory Obstacles to Financial Innovation ${ }^{13}$. According to the $9^{\text {th }}$ Recommendation in the report "The Commission, in cooperation with the ESAs, and in co-ordination with relevant authorities and international standard setters, should develop and implement a comprehensive and ambitious agenda to support the adoption of advanced RegTech and SupTech by the financial sector". The fourteenth recommendation of the report states that 
„The Commission and the ESAs should further assess the need to establish an EU-level 'regulatory sandbox', or similar scheme, taking account of the experience acquired in the context of European Forum for Innovation Facilitators" (ROFIEG, 2019, pp. 17-18).

Current technological development and levels of cooperation between regulators and financial institutions allows SupTech also to favor the development of regulatory reporting. More specifically, here could be qualified the applications for supervisory disclosure, the mechanisms for direct retrieval of data from financial intermediaries' information systems, automated data validation and consolidation, applications for analysis of misconduct (insider trading technologies, money laundering), providing regulatory control and realtime auditing options and liquidity risk monitoring systems. Improved analyzes in the field of micro- and macroprudential regulation, harmonization and obtaining feedback on the effectiveness of supervisory policies are among the other prospects of the massification of SupTech (Broeders and Prenio, 2018, p. 1; Burnmark, Alvarez \& Marsal, 2018, p. 29).

Mentioned above may raise the question does SupTech duplicate and compete with private RegTech initiatives? Employment of machine learning and artificial intelligence to examine vast data sets benefits regulators in prevention of identify breaches or cases of misconduct (Pollari et. al., 2019). Moreover, the application of this technological capacity provides supervisors with advantage "to predict risk areas that the institution does not see coming" (Pollari et. al., 2019). Here technological innovations are in support of the proactive role of supervisors. It can be also recalled that the lack of such regulatory proactivity is one of the factors led to the Global financial crisis. Their inability to assess adequately and in time emerging risks provoked by securitization, the financial innovation of that time, and all overcomplicated internal models for credit risk assessment resulted in the financial turmoil of 2007-2008. From this perspective, today`s cooperation between SupTech and RegTech sectors could be considered as learned by regulating authorities lesson that lagging behind innovations often leads to future failures.

Today we witness a number of supported by regulatory agencies joint initiatives between financial institutions and technology companies. Projects like Voltron, Marco Polo, Batavia, We.Trade, HKTFP bring together global banking institutions, technology and regulatory expertise providers and supervisory agencies in common platforms to share data, implement smart contracts, speed up transactions, prevent misconduct and fraud. In this way, a fundamentally new type of ecosystems, based on shared information and resource security, is formed (Valverde \& Fernández, 2019, pp. 23-24).

Undoubtedly, innovations implemented by regulators gravitate around the technologies for processing large data sets, their "smart" processing and analysis and the creation of "safe" blockchain-based channels for information exchange. Broeders \& Prenio 
(2018) summarize in following two categories the technological tools used by supervisory agencies in their SupTech R\&D activities: 1) data collection tools, including application programming interfaces (APIs), automated data collection mechanisms, data processing in the cloud, chatbots, and 2) data analysis tools, including individual instruments for processing large data sets, and information analysis using artificial intelligence (Broeders \& Prenio, 2018, pp. 5-6).

Presented above brief examples for incorporation of various high-tech achievements in the field of financial regulation testify for an outlined trend towards technological inclusion. And if presented above systematization classifies SupTech initiatives in terms of their technological characteristics, from institutional point of view could be outlined the following levels for generating, testing and implementing innovations in the field of financial supervision:

- Independent R\&D activities of the supervisory agencies through independent development and testing of various innovations.

- Cooperation of different SupTech and RegTech initiatives by attracting RegTech firms like partners in different SupTech ecosystems.

- Attracting traditional financial institutions like participants in different stages of the regulatory innovations` $\mathrm{R} \& \mathrm{D}$ process.

- Formation of joint test environments (like sandboxes, accelerators and innovation hubs) where participants are regulating authorities, RegTech firms and financial service providers (both traditional and FinTech).

This level of cooperation should be considered as a conditional systematization highlighting the technological expansion in the field of financial regulation. On this basis, several arguments can be presented in support of the thesis for an observed tendency for transition to a peculiar platform model for financial regulation, where SupTech and RegTech could be represented as two integrated parts of a decentralized and platformoriented financial infrastructure.

First, the growing popularity of blockchain technology outside the sphere of cryptocurrencies, and more precisely its perception for various financial purposes, including regulatory, could be taken into consideration. Information sharing platforms using DLT technology, introduced by the Singapore and Hong Kong Monetary Authorities, are already operational and prove their functionality and ability to integrate a wide range of actors into a single and secure database ${ }^{14}$. Moreover, the blockchain technology gains popularity as an alternative of traditional trade, remittance and wire transfer systems. Examples here are: The "One Pay FX" project of Santander; The Pan-Nordic bank consortium "P27"; The "Marco Polo" trade finance initiative, including 30 global banks; 
the "Komgo" consortium of 15 financial institutions; the consortium between Swiss UBS and 14 global banks; the intention of SWIFT to introduce own DLT payment infrastructure. All they illustrate the ongoing process of next level technological renovation were the DLT mechanism could support different levels of cooperation and integration.

In this regard, Auer (2019) offers the concept for embedded supervision, based on data sharing via DLT. Although the focus there is on decentralized markets, the concept is fully applicable to any market participant resorting to platform solutions. The main advantage of automated (built-in) supervisory mechanisms is the minimization of compliance costs and the achievement of equality between small and large financial service providers (Auer, 2019: 1-2).

In the area of financial regulation, similar opportunity for secure information sharing would inevitably support the creation of interactive joint databases between regulators, regulatory providers (RegTech) and regulated institutions. It is the integration of different institutions in the scope of unified databases that this can be related to the second argument, which is based on observations of already established platforms for exchange and sharing of information and expertise between regulators, financial institutions and providers of technological solutions. A joint study on the topic conducted by TheCityUK, Deloitte and Santander indicates following seven possible types of shared platforms: platforms for transactions monitoring, for collateral management, for fraud counteraction, for customer identification (KYC), for regulatory reporting, for syndicated loans processing and for trade financing ${ }^{15}$.

Third argument is related to the integration of the internal compliance organization within the general corporate governance and risk management policy (the so called triad GCR - Governance, Risk Management and Compliance) and the integration of individual compliance processes in the unified risk management policy in the respective financial institution ${ }^{16}$. Once again, technological innovations play a crucial role here, converting the silo compliance reporting systems into a "smart" alternative for regulatory compliance. This finding is supported by the ROFIEG report cited above, according to which regulatory platforms, regulatory compliance processes and information reporting can be useful in overcoming a number of regulatory disclosure challenges (ROFIEG, 2019, p. 60).

A concrete example of the importance of innovative compliance platform solutions is the expected single European whistleblowing legislation through the transposition of the Directive on the protection of persons who report breaches of Union law ${ }^{17}$. According to some authors (Staelens, 2020), a certified software platform allowing two-way encrypted communication with all internal and external stakeholders related to the specific 
irregularity signal is critical to the effective implementation of such regulations at the level of an individual financial institution.

\section{Visions for future development}

Taking into account changes highlighted above, we could summarize a few tendencies outlining the transition from a traditional bipolar dispositive model of financial regulation (regulator - regulated entities) to an interactive regulatory environment involving more participants in the supervisory process ${ }^{18}$. Main components of such technologized regulatory infrastructure are:

- The supervisory agencies as initiators of different high-tech regulatory activities.

- The regulated entities, being involved as "partners" in the supervisory process.

- RegTech providers of regulatory expertise as outsourcing partners, mainly for financial institutions, but also as participants in the common regulatory ecosystems.

- Supervisors`SupTech initiatives, for creation, testing and implementation of technological innovations.

Such a transition would inevitably be a long process, starting with the provision of technological resources provided by different blockchain, big data and AI solutions.

In short-term could be expected in-depth cooperation between the RegTech and SupTech sectors especially in the field of sharing data and resources. From a technological point of view, this would require additional development of already started processes of automation and robotization of some compliance operations and processes. It is reasonable expectation that the implementation of innovative solutions based on blockchain, large data sets processing, computing in cloud environment and usage of different AI tools will continue to rise. From a normative point of view, there is an urgent need to develop a regulatory and supervisory framework for new services such as virtual and crypto asset management or alternative financing (Gonzalez-Paramo, 2018). The shift from physical structures of local importance to globalized network structures also requires development of even more global financial regulations, following the example of Basel IV, but aimed at a wider range of financial service providers. (Skinner, 2019).

The preamble of the proposed by the Euro Commission in 2020 Regulation on Markets in Crypto-assets (MiCA) demonstrates the beginning of such policy implementations. More precisely, it is stated that "the EU financial services regulatory framework is innovation-friendly and does not pose obstacles to the application of new technologies. This proposal, together with the proposal on a DLT pilot regime, represents the first concrete action within this area". As pointed in the European Commission Proposal, such normative initiatives "create an EU framework that both enables markets in 
crypto-assets as well as the tokenisation of traditional financial assets and wider use of DLT in financial services" (European Commission, 2020).

In nearest perspective the consequences of the COVID-pandemic are already being considered. It sounds paradoxical, but it is already provoking some positive reflections on banking activities, mostly because it "will accelerate the convergence of digital and physical" (Pylarinou, 2020), forcing innovations to "come from the core part of the business. Up to now the path of least resistance for many traditional institutions has been to set up a digital bank that runs in parallel to the main institution. Now, the business case for running a multi-brand strategy with your own challenger bank running beside your core bank is going to be far weaker, because the question will be asked, "Why aren't you doing that with the main bank?" (Streeter, 2020).

It is known, for example, that today "are now making decisions about cloud-based operations and permanently having staff at home, with technology decisions that have been bubbling away for years being made in weeks" (Skinner, 2020). However, some of them still do not have an adequate regulatory projection, which (among other things) must take into account the greater decentralization of the digital economy caused by technological innovation ${ }^{19}$.

COVID-19 could also be associated with high hopes to catalyze the work of legislators and regulators on "introducing Open banking. Perhaps the only way banks will truly embrace the new data/AI ecosystem is if they are compelled to do so via a secondary wave of legislation - aka Open Banking 2.0" (Gauhman, 2020). It is seen by somebody like an alternative to merging between banking data centers. The newly created "open" platform could successfully compete with large and "data-driven" platforms from the US and China, which are entering the European financial market. ${ }^{20}$

The technologicalization of the regulatory process is indisputable, but the ubiquitous application of regulatory innovations is still limited. Some interpret this circumstance as a reaction to fears of regulatory requirements (McIntyre et al., 2018, p. 17). According to others, their use (for example by robotic consultants in the investment process) has a high potential for growth, but stricter regulation would result in loose of simplicity (Hartdegen u.a., 2019, S. 15). For example, offered today Robo Advice and digital asset management represent a step towards platform service of "normally rich" clients (Affluents) with standardized or automated offers, rather than an emanation of a new Private Banking model. This is because the "higher" asset segments, resp. the needs of many and ultra-rich clients, are too complex and do not submit to standardized investment decisions. ${ }^{21}$

In a longer-term perspective, however, a complete redesign of the existing regulatory infrastructure could be expected. The complete automation of operational compliance 
activities, the fully automated interaction between financial institutions and supervisory agencies, together with the integration of external providers of regulatory expertise within the scope of a single platform model outline its future appearance.

However, a series of questions on adapting regulatory changes to the risk potential of innovative technologies like smart algorithms, for example, which "are often portrayed as some sort of panacea, solving business need and consumer service" (Risk \& Compliance Platform Europe, 2020) also awaits a timely solution. For example, how will be treated the risks of "smart" machine solutions? To what extent could be included risk-based machine learning techniques providing easier regulation of payment fraud for customers? And is it possible to "construct" a regulatory framework of risks provoked by morally dubious decisions, which no one has foreseen and there is no possibility for direct control over them? Who and at what cost will be responsible for the consequences of one or another "catastrophic" decision of the artificial system?

\section{Funding and acknowledgements}

This research has received funding from the European Union's Horizon 2020 research and innovation program FIN-TECH: A Financial supervision and Technology compliance training programme under the grant agreement No 825215 (Topic: ICT-352018, Type of action: CSA).

\section{REFERENCES:}

Auer, R. (2019). Embedded Supervision: How to Build Regulation into Blockchain Finance, Bank for International Settlements, [Online]. Available at: https://www.bis.org/publ/work811.pdf.

Barberis, J. D. Arner, R. Buckley (2019). The REGTECH Book: The Financial Technology Handbook for Investors, Entrepreneurs and Visionaries in Regulation. Wiley.

Basel Committee on Banking Supervision, BCBS (2017). Sound Practices: Implications of fintech developments for banks and bank supervisors. Consultative Document. Issued for comment by 31 October 2017, [Online]. Available at: https://www.bis.org/bcbs/publ/d415.pdf.

Basel Committee on Banking Supervision, BCBS (2018). Sound Practices: Implications of Fintech Developments for Banks and Bank Supervisors, [Online]. Available at: https://www.bis.org/bcbs/publ/d431.pdf.

Broeders, D., J. Prenio (2018). Innovative technology in financial supervision (suptech) - the experience of early users // FSI Insights on policy implementation, No 9, July 2018, [Online]. Available at: https://www.bis.org/fsi/publ/insights9.pdf.

Bundesverband deutscher Banken (2020). Cloud Computing bei Banken, 21. August, 2020. [Online]. Available at: https://bankenverband.de/themen/cloud-computing-bei-banken/. 
Burnmark, Alvarez \& Marsal (2018), RegTech 2.0, [Online]. Available at: https://www.alvarezandmarsal.com/sites/default/files/regtech_2.0_report_final.pdf.

Congressional Research Service (2020). Fintech: Overview of Innovative Financial Technology and Selected Policy Issues, April 28, 2020. [Online]. Available at: https://crsreports.congress.gov/product/pdf/R/R46332.

Deloitte (2016). RegTech is the new FinTech. How agile regulatory technology is helping firms better understand and manage their risks. [Online]. Available at: https://www2.deloitte.com/content/dam/Deloitte/ie/Documents/FinancialServices/IE_2016_F S_RegTech_is_the_new_FinTech.pdf.

Deloitte (2020). Does Blockchain mean an end to regulatory reporting as we know it?, [Online]. Available at: https://www2.deloitte.com/uk/en/pages/financial-services/articles/doesblockchain-mean-an-end-to-regulatory-reporting.html.

Dzhaparov, Pl. (2020). Application of blockchain and artificial intelligence in bank risk management. // Economics and Management, Vol. XVII, Issue: 1, pp.43-57.

ESMA, EBA, EIOPA (2019). FinTech: Regulatory sandboxes and innovation hubs, Report. JC 2018 74, [Online]. Available at: https://esas-jointcommittee.europa.eu/Publications/Reports/JC\%202018\%2074\%20Joint\%20Report\%20on\%2 0Regulatory\%20Sandboxes\%20and\%20Innovation\%20Hubs.pdf.

European Central Bank (2020). ESCB/European banking supervision response to the European Commission's public consultation on a new digital finance strategy for Europe/FinTech action plan. August 2020. [Online]. Available at: https://www.bankingsupervision.europa.eu/ecb/pub/pdf/ssm.esbceuropeanbankingsupervisio nresponsetoeuropeancommissionpublicconsultationdigitalfinancestrategyeuropefintechaction plan2020 b2e6cd0dc4.en.pdf.

European Commission (2020). Proposal for a Regulation of the European Parliament and of the Council on Markets in Crypto-assets, and Amending Directive (EU) 2019/1937, [Online]. Available at: https://eur-lex.europa.eu/legalcontent/EN/TXT/?uri=CELEX\%3A52020PC0593

European Commission (2019). Directorate-General for Financial Stability, Financial Services and Capital Markets Union (FISMA). Study on the costs of compliance for the financial sector. Final Report. [Online]. Available at: https://op.europa.eu/en/publication-detail//publication/4b62e682-4e0f-11ea-aece-01aa75ed71a1

Expert Group on Regulatory Obstacles to Financial Innovation (ROFIEG) (2019). 30 Recommendations on Regulation, Innovation and Finance. Final Report to the European Commission, December 2019, [Online]. Available at: https://ec.europa.eu/info/sites/info/files/business_economy_euro/banking_and_finance/docu ments/191113-report-expert-group-regulatory-obstacles-financial-innovation_en.pdf.

Financial Conduct Authority, FCA (2015). Call for Input: Supporting the development and adoption of RegTech, [Online]. Available at: https://www.fca.org.uk/publication/call-for-input/regtechcall-for-input.pdf. 
Financial Stability Board (2020). The Use of Supervisory and Regulatory Technology by Authorities and Regulated Institutions: Market developments and financial stability implications, 9 October 2020, [Online]. Available at: https://www.fsb.org/wp-content/uploads/P091020.pdf.

FinTech Global (2019). More than \$9.5bn has been invested in RegTech companies globally over the last five years. [Online]. Available at: https://fintech.global/more-than-9-5bn-has-beeninvested-in-regtech-companies-globally-over-the-last-five-years/.

Gauhman. L. (2020). 4 Digital Transformation Lessons that Banks Need to Learn from Covid-19. // Finextra Research, 20 May, 2020, [Online]. Available at: https://www.finextra.com/blogposting/18776/4-digital-transformation-lessons-that-banksneed-to-learn-from-covid-19.

Gonzalez-Paramo, J. M. (2018). Opportunities and challenges for banking regulation and supervision in the digital age. SUERF Policy Note, Issue No 31, April 2018, [Online]. Available at: https://www.suerf.org/policynotes/2511/opportunities-and-challenges-forbanking-regulation-and-supervision-in-the-digital-age/html.

Hartdegen, Chr., A. Peters, St. Weber (2019). KI-unterstützte Automation an der Kunde-BankSchnittstelle. // ibi Research Report, ibi research an der Universität Regensburg, Oktober, https://ibi.de/veroeffentlichungen/ki-unterstuetzte-Automation-an-der-kunde-bankschnittstelle.

Kumar, S. (2020). Digital Transformation of Regulatory Compliance for Financial Institutions. // MEDICI, May 27, [Online]. Available at: https://gomedici.com/digital-transformation-ofregulatory-compliance-for-financial-institutions?_s=8fgunq2isrsqtt5tmhri.

Iansiti, M., K. R. Lakhani (2019). Competing in the Age of AI. // Harvard Business Review, From the January-February 2020 Issue, [Online]. Available at: https://hbr.org/2020/01/competingin-the-age-of-

ai?utm_source=facebook\&utm_campaign=hbr\&utm_medium =social\&fbclid=IwAR3wmk3F bE2xY4YBToSkySSW3TNNXC79Q3OASfs-yoiEU2D4fAFtFOGbLOk

McIntyre, A., C. Rainusso, Fr. Rohde, J. Bant (2018). Want Bank Revenue Growth? Price For Customer Lifetime Value. 2018 RETAIL BANK PRICING SURVEY.// Accenture, [Online]. Available at: https://www.accenture.com/_acnmedia/accenture/conversionassets/dotcom/documents/global/pdf/dualpub_20/accenture-retail-bank-pricing-survey.pdf.

McKinsey \& Company (2020). The 2020McKinsey Global Payments Report. [Online]. Available at:

https://www.mckinsey.com/ /media/mckinsey/industries/financial\%20services/our\%20insigh ts/accelerating $\% 20$ winds $\% 20$ of $\% 20$ change $\% 20 \mathrm{in} \% 20$ global $\% 20$ payments/2020-mckinseyglobal-payments-report-vf.pdf

Nedelchev, M. (2020). Origin and Definition of RegTech. // Economics and Management, Vol. XVII, Issue: 1, pp.1-9.

Payments NEXT (2020). Regtech compliance disruption growing; spending will reach \$115.9 billion, [Online]. Available at: https://paymentsnext.com/regtech-compliance-disruptiongrowing-spending-will-reach-115-9-billion/.

Pollari, I., D. Milligan, Ch. Steele, F. Gobbno (2019). Regtech beyond compliance. How can banks, asset managers and insurers determine the right regtech solution for their needs? KPMG. 
[Online]. Available at: https://home.kpmg/xx/en/home/insights/2019/03/beyond-compliancefs.html.

Pylarinou, E. (2020). COVID-19 is a catalyst for business innovation. Daily Fintech. [Online]. Available at: https://dailyfintech.com/2020/03/10/covid-19-is-a-catalyst-for-businessinnovation/.

Risk \& Compliance Platform Europe. (2020). Christopher Woolard asks himself: "What kind of regulations do we want?", 22 September 2020. [Online]. Available at: https://www.riskcompliance.biz/news/christopher-woolard-asks-himself-what-kind-ofregulations-do-we-want/.

Schizas, E., Gr. McKain, Br. Zhanig et al. (2019). The Global RegTech Industry Benchmark Report. Cambridge Centre for Alternative Finance. [Online]. Available at: https://www.jbs.cam.ac.uk/wp-content/uploads/2020/08/2019-12-ccaf-global-regtechbenchmarking-report.pdf

Skinner, Ch. (2017). Bank Regulations Change Every 12 Minutes. The Finanser. Chris Skinner`s Blog. [Online]. Available at: https://thefinanser.com/2017/01/bank-regulations-change-every12-minutes.html/

Skinner, Ch. (2019). Time for a global regulator. TheFinanser, Apr 4, [Online]. [Online]. Available at: https://thefinanser.com/2019/04/time-for-a-global-regulator.html/.

Skinner, Chr. (2020). This is no Black Swan. // The Finanser, May 26, 2020, [Online]. Available at: https://thefinanser.com/2020/05/this-is-no-black-swan.html/.

Staelens, Fr. (2020). Whistleblowing Management: The Coming Regulatory Storm. // Risk \& Compliance Platform Europe, 4 August 2020, [Online]. Available at: https://www.riskcompliance.biz/news/whistleblowing-management-the-coming-regulatorystorm/.

Streeter, B. (2020). Pandemic Gives Traditional Banks a Rare Chance to Catch Up Digitally. // The Financial Brand, May 18, 2020, [Online]. Available at: https://thefinancialbrand.com/96505/covid-digital-banking-fintech-traditional-branch/.

TheCityUK, Deloitte, Santander (2018). Splitting the Bill. The role for shared platforms in financial services regulation. November 2018, [Online]. Available at: https://www2.deloitte.com/content/dam/Deloitte/uk/Documents/financial-services/deloitteuk-thecityuk-splitting-the-bill-the-role-for-shared-platforms-in-financial-servicesregulation.pdf.

U.S. Department of the Treasury (2018). A Financial System That Creates Economic Opportunities. Nonbank Financials, Fintech, and Innovation. Report to President Donald J. Trump. Executive Order 13772 on Core Principles for Regulating the United States Financial System, [Online]. Available at: https:/home.treasury.gov/sites/default/files/2018-07/A-Financial-System-thatCreates-Economic-Opportunities---Nonbank-Financi....pdf.

Valkanov, N. (2019a). Compliance v pomosht na finansovoto regulirane. Varna: Nauka I ikonomika.

Valkanov, N. (2019b). Mitigation of Regulations Burden in Financial Sector by Application of High Tech Solutions // Economics and Management, Vol. XVI, No 1, pp. 19-30. 
Valverde, C., Fr. Fernández (2019). The future of blockchain in the European banking system. // Funcas SEFO, Vol. 8, No. 1, January 2019, [Online]. Available at: https://www.sefofuncas.com/pdf/Carbo 8.1.pdf.

${ }^{1}$ A research of the European Commission reports that in 2017 the compliance costs form on average between 2 and $4 \%$ of the total operating costs in industries like banking, insurance, asset management and securities operations. The largest share of the operating compliance costs is taken by regulatory reporting costs $-30 \%$ on average of the one-off and $27 \%$ of the ongoing costs (European Commission, 2019, p. 7).

${ }^{2}$ For the regulatory reformatting that followed the global financial crisis of 2007-2008 and the burden of over-regulation see: Valkanov 2019a, pp. 38-57.

${ }^{3}$ RegTech (from Regulatory Technology) is a collective term, generalizing the application of advanced information technologies for the needs of financial regulation. A detailed functional definition for RegTech is given by the Cambridge Centre for Alternative Finance (CCAF) - see: Schizas et al., 2019, pp. 18-19; On the origin and evolution of RegTech see also Nedelchev, 2020, pp. 1-9.

${ }^{4}$ According to Barberis et al. (2019) the appearance of RegTechs dates since the 90s and the first years of the new millennium and could be associated primarily with the development of own technologies for risk management reporting and measurement (Value at Risk) in accordance with the capital regulations in force at the time, as well as with the compliance with regulatory requirements for monitoring abnormal movements in the securities markets. To some extent, it is the overconfidence of this first wave of technological innovation (RegTech 1.0) that contributed to the 2007 financial crisis. Following increased post-crisis regulatory requirements provoke the emergence of their modern version (RegTech 2.0), focusing on digitalization and the importance of data for the needs of regulatory compliance and supervisory disclosure - see: Barberis et al., 2019, pp. viii-ix.

${ }^{5}$ The application of blockchain and AI in bank risk management is discussed in Dzhaparov, 2020, pp.43-57.

${ }^{6}$ In details for different RegTech variations see: Deloitte, 2018; Schizas et al., 2019.

${ }^{7}$ See: Valkanov, 2019a, pp. 176-186. Compared to other industries, the management of sensitive data at the highest level is not unknown to the financial sector and especially to the banks. On the contrary, many credit institutions have well-established procedures for managing confidential and sensitive information, for example in the areas of Corporate and Investment Banking. In this sense, the new data protection directive (General Data Protection Regulation, GDPR) is another challenge for observing and ensuring the inviolability of personal user data, which exists in large volumes and is "scattered" in many groups.

${ }^{8}$ See: European Central Bank, 2020, pp. 11-12.

${ }^{9}$ For example, see: Financial Conduct Authority, 2015; Broeders and Prenio, 2018; U.S. Department of the Treasury, 2018; Financial Stability Board, 2020; Congressional Research Service, 2020.

10 See: Basel Committee on Banking Supervision, 2018, p. 24; Auer, 2019, pp. 19-20; U.S. Department of the Treasury, 2018, p. 13; Financial Conduct Authority, 2015, p. 5.

${ }^{11}$ In details for each of them see: Valverde \& Fernández, 2019, p. 28.

${ }^{12}$ More than 50 national financial regulators have announced their current or forthcoming initiatives in this direction. A detailed list is published on following URL: 
https://dfsobservatory.com/content/regulatory-sandboxes. Detailed statistics on regulatory sandboxes and innovation hubs in EU countries are provided by ESMA, EBA and EIOPA, 2019.

13 The Expert Group on Regulatory Obstacles to Financial Innovation (ROFIEG) is established in 2018 by the European Commission in order to assist the Commission by providing high-level expertise on EU financial services legislation in relation to financial technology. See: https://ec.europa.eu/info/publications/180308-fintech-call-for-applications_en.

14 The McKinsey 2020 Global Payments Report confirms the benefits from "different sharedutility opportunities (...) in joint know-your-customer (KYC) and fraud-prevention initiatives" (McKinsey, 2020, p. 30).

${ }^{15}$ See: TheCityUK, Deloitte, Santander, 2018, p. 10.

${ }^{16}$ More about the application of the platform model in the field of regulatory compliance see in: Valkanov, 2019a, p. 170-175.

${ }^{17}$ Directive (EU) 2019/1937. First whistleblowing legislation was introduced in the United States in 1989 by the Whistleblower Protection Act. In the United Kingdom a similar enactment is the Public Interest Disclosure Act (PIDA) of 1998.

${ }^{18}$ For more details on expected changes in the financial regulation sector see: Valkanov, 2019b.

${ }^{19}$ According to the German Banking Association "today's regulation is not yet sufficiently designed for the widespread use of the cloud by banks" and "in order to change this, the following adjustments are needed in particular: 1. The regulation of cloud outsourcing must be based on risk-based approach. 2. Reporting requirements for supervisors and exit strategies must be clear and uniform across Europe. 3. In order to minimize the risks of concentrating on several cloud providers, standards must be put in place that create seamless portability between cloud providers." (Bundesverband deutscher Banken, 2020).

${ }^{20}$ Introduction of open banking frameworks in the European Union, the United Kingdom, India, Hong Kong and Singapore raises expectations of an "explosion" of third-country providers that seize "territory" from traditional credit institutions (...). Although the United States has not taken a regulatory approach to "open banking", the country "does not lag behind the rest of the world" and "demonstrates great activity that reflects "open banking", even if it is not labeled as such." (Streeter, 2020).

${ }^{21}$ Compared to traditional private banking, new platforms possess some indisputable advantages: the potential to create more critical mass and "big data", the lack of "own" systems, reduced regulatory complexity, etc. Not from the point of view of trusting personal relationships between clients and consultations, as a differentiated value of the offer factor, some see in platform models "investment ruins". 